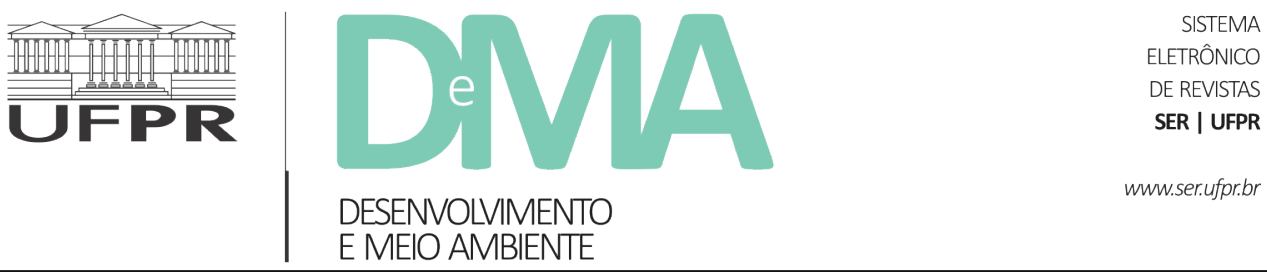

\title{
Participação social na Reserva Extrativista Marinha de Arraial do Cabo: uma análise dos instrumentos de gestão sob a ótica da decolonialidade
}

\section{Social participation in the Arraial do Cabo Marine Extractive Reserve: an analysis of management tools from a perspective of decoloniality}

\author{
Valéria Penchel ARAÚJO ${ }^{1 *}$, Omar Souza NICOLAU ${ }^{1}$ \\ ${ }^{1}$ Instituto Federal de Educação Ciência e Tecnologia do Rio de Janeiro - IFRJ, Rio de Janeiro, RJ, Brasil. \\ *E-mail de contato: valpenchel@hotmail.com
}

Artigo recebido em 9 de abril de 2018, versão final aceita em 13 de agosto de 2018.

\begin{abstract}
RESUMO: A presente proposta busca uma trajetória de análise que inclui a dinâmica da participação social em Unidades de Conservação de Uso Sustentável. Para tanto, propõe-se explorar a resposta do movimento seringueiro às ameaças de avanço do desenvolvimentismo entre as décadas de 1970-80, até a apropriação desse legado por parte de agentes como o estado e o mercado. Sugere-se um estudo crítico à luz dos esforços teóricos que abrangem o pensamento decolonial, entrecruzando uma perspectiva que compreenda os processos sociais a partir da resistência dos movimentos sociais de um lado e, de outro, da apropriação de suas proposições. Dessa forma, o que fora construído como luta por um reconhecimento de uma forma específica de relação com o território, um modelo de desenvolvimento alicerçado na organização de uma economia local, associada diretamente a um modo específico de fazer, viver e criar "desde o sul", pretende-se examinar a conversão daquilo que se tornou uma política pública, a Resex, nesse caso marinha, em espaços institucionais que aprisionam a possibilidade da proposta emancipatória contida nos enunciados do movimento seringueiro. A Reserva Extrativista Marinha de Arraial do Cabo, criada em 1997, proporciona visualizar a implementação dessa política pública num território marinho, onde os processos social, cultural, econômico e político são atualizados. O enfoque nos chamados instrumentos de gestão, tais como o Conselho Deliberativo, a Concessão do Direito Real de Uso, Plano de Utilização e o Acordo de Gestão, constituirá um diálogo teórico-prático que parte da comunicação da resistência de pescadores e pescadoras à iniciativas de tutela por parte do estado e de outros agentes, trazendo à luz a percepção desses sujeitos nas atuais arenas de decisão instituídas por força legal.
\end{abstract}

Palavras-chave: Resex Marinha de Arraial do Cabo; participação social; decolonialidade; instrumentos de gestão. 
ABSTRACT: The present proposal seeks an analysis of the dynamics of social participation in Conservation Units of Sustainable Use. In order to do so, it explores the response of the social movement of the rubber-tree to the threats of Developmentalism between the 1970s and 1980s, to the appropriation of this legacy by agents such as the tate and the market. A critical study is suggested in the light of the theoretical efforts that cover decolonial thinking, intersecting a perspective that understands social processes from the resistance of social movements on the one hand, and from the appropriation of their proposals on the other.. In this way, what was built as a struggle for recognition of a specific form of relationship with the territory, a development model based on the organization of a local economy, directly associated with a specific way of doing, living and creating "from the South has become a public policy, a marine protected area, with institutional spaces that imprison the possibility of the emancipatory proposal contained in the statements of the rubbertapper movement. The Arraial do Cabo Marine Extractive Reserve, created in 1997, provides an overview of the implementation of this public policy in a marine territory, where social, cultural, economic and political processes are updated. The focus on the so-called management instruments, such as the Deliberative Council, the Concession of the Real Right of Use, the Plan of Use, the Management Agreement, will constitute a theoretical-practical dialogue that stems from the communication of the resistance of fishermen to initiatives of guardianship by the state and other agents, bringing to light the perception of these subjects in the current arenas of decision instituted by legal force.

Keywords: Resex Marinha de Arraial do Cabo; social participation; decoloniality; management tools.

\section{Introdução}

$\mathrm{O}$ arcabouço analítico fornecido pelas teorias decoloniais elaboradas, em grande parte pelo grupo de estudos Modernidade/Colonialidade ${ }^{1}$ na América do Sul, fornecem análises que permitem a atualização crítica do pensamento latino americano, a partir de uma releitura histórica do projeto colonial e da compreensão das diversas formas de colonialidade presentes na América Latina. Sem, no entanto, sistematizar uma "teoria geral" da colonialidade, mas avançando nas perspectivas das correntes pós-estruturalistas e pós-coloniais, tais estudos têm ajudado pesquisadores do Hemisfério Sul a compreender fenômenos sociais, políticos, econômicos e de produção do saber, a partir do complexo projeto da modernidade, que impõe para dentro e para fora dos Estados nacionais, mecanismos de dominação e subjugação. A leitura da luta dos seringueiros a partir da ótica decolonial nos parece um fecundo exercício tanto para caracterizar de que forma a colonialidade, no interior da modernidade estiveram presentes na ocupação da Região Norte brasileira no último século, quanto para argumentar sobre o conteúdo decolonial presente na própria formação e estratégias de luta desse grupo, e nas reivindicações que culminaram na criação das reservas extrativistas. É importante ressaltar que não estamos pretendendo nenhuma transposição mecânica de uma perspectiva analítica que tenta encaixar artificialmente a pujança do fenômeno social a uma tipificação ou classificação estéril. Diferentemente,

\footnotetext{
${ }^{1}$ Este grupo foi constituído no final dos anos 1990 e composto por intelectuais latino-americanos situados em diversas universidades das Américas e oriundos de diversas áreas de conhecimento, cujo o coletivo realizou um movimento epistemológico fundamental para a renovação crítica e utópica das ciências sociais na América Latina no século XXI. Trata-se de autores como Walter Mingolo, Aníbal Quijano, Enrique Dussel, Catherine Walsh, Arthuro Escobar entre outros (Ballestrin, 2014).
} 
o presente trabalho quer iluminar, com o aporte da decolonialidade, as propostas genuínas de luta e de comunicação de identidade, cosmologias do movimento seringueiro e sua proposta de extrativismo popular a uma interpretação que o afilia às tentativas de emancipação por parte de grupos sociais subalternos na América Latina. Ao mesmo tempo, o referencial da decolonialidade nos possibilita apontar também diversas contradições e distorções que as propostas originais vêm sofrendo a partir, principalmente, de sua institucionalização e apropriação por outros agentes, inclusive o Estado, subjugando-as novamente às imposições epistêmicas, políticas e econômicas inclusas na lógica da modernidade colonial. Para tanto, o fio condutor dessa análise dar-se-á a partir dos conceitos de Autonomia, Participação Social e Gestão Compartilhada, contidos de diferentes formas na idealização e implementação de um território protegido, inicialmente gestado nas entranhas de um movimento social, sua transposição para nichos ecológicos diferentes do da floresta, no nosso caso o marinho, e a resultante de políticas universais que procuram absorver particularidades locais. Nesse sentido, faremos um diálogo entre as diversas leituras que retratam o contexto dos seringueiros à época da elaboração da proposta de Resex, sua organização, princípios e estratégias de luta, procurando apontar elementos que evidenciam tanto a colonialidade do contexto, quanto o giro decolonial $^{2}$ da proposta, com a atual perspectiva de Autonomia, Participação Social e a Gestão Compartilhada na Reserva Extrativista Marinha do Arraial do $\mathrm{Cabo}^{3}$. A interlocução dessas diferentes perspectivas nos permite observar a atualização das formas de apropriação da proposta de reserva extrativista inventada por Chico Mendes e o movimento dos seringueiros da Amazônia, pelos movimentos sociais em Arraial do Cabo, e da "modernização" dos instrumentos de gestão, promovida pelo Estado.

Para fins deste trabalho, lançamos mão de uma categoria chamada pelos órgãos do Estado brasileiro de "instrumentos de gestão". Compreende aqui o Plano de Utilização/Acordo de Gestão, o Conselho Deliberativo, a Concessão do Direito Real de Uso e o Plano de Manejo. Tais instrumentos serão aqui abordados na perspectiva que Souza Lima (2002) confere, a partir de estudos da Política Indigenista do Brasil sob o tratamento da tutela, em que se sobrepõem as funções de Estado e, por conseguinte, seus instrumentos de gestão, a comportar o papel de gestar e de gerir. Segundo o autor:

'Gestar' aponta-nos para a função constitutiva e peda-
gógica da 'maternagem', do ensinar a 'ser', perceptível
na tutela como exercício de poder de que a imagem de
'babá' ou 'governanta' e sua bondade opressiva são em-
blemáticas, uma dimensão de instauração, pelo desejo do
'bem', deste novo coletivo, segmentos concebidos como
constitutivamente despossuídos das condições mínimas
para a vida social em pé de desigualdade. 'Gerir' sinali-
za-nos ao controle cotidiano de administração que, débil,
perpassada por interesses pessoais e de redes de clientelas
que seja, onde os interesses de grupos são muito mais
fortes que os chamados corporativos, por vezes mais figu-
ração do que prática efetiva, ainda assim representa este
"tutor" de coletivos, controlador de espaços, mantenedor
dos desiguais em seus nichos. (Souza Lima, 2002, p. 16)
Para Souza Lima e outros autores que se debruçam sobre
a análise da administração pública no Brasil, a partir de
uma perspectiva antropológica, uma ênfase dada aos
processos atuais de articulação Sociedade Civil - Estado,
sob os auspícios da participação social, convida-nos a

\footnotetext{
${ }^{2}$ Expressão cunhada pelo Grupo Latino-americano de Estudos Subalternos, mais tarde Modernidade/Colonialidade (M/C).

${ }^{3}$ A aproximação do objeto analítico deste artigo a partir da Resex Mar AC só é possível pois os autores vêm acompanhando sua implementação por meio de pesquisas desenvolvidas a partir do programa de Pós-Graduação em Ciências Ambientais em Áreas Costeiras, oferecido pelo Instituto Federal de Educação, Ciência e Tecnologia - IFRJ - Campus Arraial do Cabo.
} 
realizar uma análise que leve em conta permanências na correlação de forças no âmbito da Sociedade Civil, dentro de uma perspectiva modernizante e participativa prescrita pelo Estado.

Há então um movimento para que o Estado albergue as fissuras identitárias para fins de reconhecimento de direitos territórios, e os modos de fazer, viver e criar das ditas populações tradicionais, que costuma aparecer na literatura como marco, ao menos no que diz respeito ao sociambientalismo, na luta dos seringueiros, e à forma como a participação e autonomia foi engendrada, testada e praticada pelo Estado brasileiro na gestão de áreas protegidas de uso sustentável.

\section{A noção de Reserva Extrativista dos seringueiros}

A situação dos seringueiros na Amazônia no fim do século XIX e século XX, à mercê da economia da borracha, do sistema de aviamento e dos diversos projetos desenvolvimentistas tocados pelo Estado brasileiro, são evidências latentes de que o fim do colonialismo na América não representou o fim da colonialidade 4 . A luta de Chico Mendes e dos seringueiros desde sua origem até os dias atuais se faz justamente pela necessidade do reconhecimento dos seringueiros como povo da floresta, detentor de uma cosmovisão e de um modo de vida que mesmo submetido ao sistema-mundo ${ }^{5}$ em determinado mo- mento se opõe à "colonialidade do poder, do saber e do ser" (Quijano, 2005). A vida dos migrantes nordestinos atraídos pelo trabalho na extração do látex nos seringais nativos no fim do século XIX, e que ali na Amazônia sobreviveram na invisibilidade, foi submetida à violência de um regime análogo à escravidão e que atravessou os diversos ciclos da borracha. Por meio da ressonância de suas estratégias de luta pacíficas e suas propostas arrojadas que apontaram para a necessidade da compreensão de um novo conceito de território, o eixo principal está na tentativa de emancipação dos seringueiros do jugo imposto para eles pelo Estado e pelo capital, em termos de hierarquias, lugares e papéis sociais, num mundo marcado pela colonialidade (Quijano, 2005). A recusa dos seringueiros em se ajustar aos padrões de loteamento impostos pelo Instituto Nacional de Colonização e Reforma Agrária - Incra -; a sua vinculação holística com a floresta que se afasta da ideia de extração exaustiva da natureza, e tem na manutenção da "floresta em pé" sua sustentabilidade econômica e social; a negativa por parte dos seringueiros em receber as indenizações que não garantiriam por si só a manutenção de seu modo de vida e nem a posse da terra, assim como sua forma de organização e de ação, evidenciam a importância do movimento seringueiro como sujeito histórico que ousou propor, com base em outros saberes a partir do local, a partir da floresta e, portanto,

\footnotetext{
${ }^{4}$ Apesar do colonialismo ter findado com as independências das colônias no século XIX na América Latina, seu projeto pode ser descrito na noção de colonialidade, pois o residual da formação social e política dessas sociedades nessa herança ainda persiste, "manifestando-se das mais variadas maneiras em nossas instituições políticas e acadêmicas, nas relações de dominação/opressão, em nossas práticas de sociabilidades autoritárias, em nossa memória, linguagem, imaginário social, em nossas subjetividades, e, consequentemente, na forma como produzimos conhecimento" (Cruz, 2017, p. 15).

${ }^{5}$ Em diálogo com Wallerstein, Aníbal Quijano utiliza-se da ideia de um sistema composto por estruturas e epistemes que são responsáveis por promoverem o padrão de poder mundial, o sistema mundo global. São elas: a empresa capitalista, no controle do trabalho, de seus recursos e produtos; a família burguesa, no controle do sexo, de seus recursos e produtos; o Estado-nação no controle da autoridade, seus recursos e produtos e, no controle da intersubjetividade, o eurocentrismo. Essas estruturas existem com uma relação de interdependência umas com a outras, configurando um sistema (Quijano, 2005, p. 123).
} 
desde o sul para o sul, a construção de um projeto de política pública. Esses sujeitos subalternizados passam a ter voz, cunhando o conceito de reserva extrativista, o que, de acordo com Carlos Walter Porto Gonçalves (2003), revoluciona os próprios fundamentos filosóficos hegemônicos na matriz da racionalidade da moderna sociedade ocidental, ao associar dois termos que tradicionalmente se excluem, que são a exploração da natureza e a conservação dos recursos naturais (Porto-Gonçalves, 2003, p. 560).

A opção pela terra coletiva também foi uma notável estratégia articulada pelo movimento no sentido de reposicionar o papel do Estado, retirando-o por um momento da perspectiva democrática liberal e seu papel funcional ao capital, ao delegar a ele a função de garantir a segurança necessária à manutenção do modo de vida dos extrativistas.

Outro aspecto central da proposta elaborada por aqueles atores e que está na base do Movimento Seringueiro (Cunha, 2010; Gonçalves, 2003; Almeida, 2004; Alegretti, 2002), e a mais relevante para a nossa análise neste artigo, é o formato proposto de administração dos territórios das reservas extrativistas baseada na "autonomia, na autogestão, no autogoverno de suas áreas" (Cunha, 2010, pag. 111), em que as regras de uso e a organização para a tomada de decisão sobre questões de seus territórios seriam tomadas exclusivamente pelos seringueiros.

De acordo com Gonçalves, a dimensão da autonomia dos seringueiros, e que vai influenciar na proposta e conceito de reservas extrativistas por eles criadas, abrange um valor instituinte, coformador do próprio padrão de organização do espaço acreano desde a década de 1920, que por sua vez foi influenciado por três fatores distintos: o isolamento em função da dispersão espacial da colocação-seringal e o fazer solitário das diversas etapas do processo produtivo; a possibilidade de utilização de uma matriz de racionalidade própria ao associar valor e medida às coisas; e do orgulho da relação ao território. Dessa forma, em diálogo com Pierre Bourdieu, o autor conclui que o sentido de autonomia percorre a vida do seringueiro seja como história corporificada em habitus, seja como cotidiano do seu espaço de vida enquanto habitat. A dimensão da autonomia construída pelo seringueiro, principalmente seringueiro liberto ${ }^{6}$, também é influenciada pela sua liberdade em negociar seu produto livremente "e, mesmo o seringueiro cativo, aquele que está subordinado ao patrão, essa autonomia diante do processo direto do trabalho, será fonte de conflitos" (Porto-Gonçalves, 2003, p. 238).

\section{Autonomia e participação social na noção de reserva extrativista no Decreto de 1990 e no Sistema Nacional de Unidades de Conservação, Snuc}

O conceito de reserva extrativista já havia sido delineado desde de 1985, durante o primeiro Encontro Nacional dos Seringueiros, numa tática específica que encontrava no ambientalismo na Amazônia um parceiro de última hora para dar visibilidade à sua luta, mas, em função do caráter arrojado da proposta dos seringueiros, havia uma dificuldade, por parte do Estado, de enquadramento das reivindicações no arcabouço tecnoburocrático e jurídico brasileiro vigente. Como se tratava de um conflito relativo à terra, a contenda foi direcionada primeiramente ao Incra, órgão responsável pela

\footnotetext{
${ }^{6}$ Seringueiro liberto também tratado por vários autores como seringueiro autônomo.
} 
colonização e reforma agrária que, como nos conta Alegretti, cria os chamados Projetos de Assentamentos Extrativistas.

O primeiro formato legal dessa proposta, nos termos de-
finidos pelo Conselho Nacional dos Seringueiros, surgiu
no âmbito do Incra. A Portaria n. ${ }^{\circ} 627$, de 30 de julho de
1987, criou a modalidade de Projeto de Assentamento
Extrativista destinado à exploração de áreas dotadas de
riquezas extrativistas, por meio de atividades economi-
camente viáveis e ecologicamente sustentáveis a serem
executadas pelas populações que ocupem ou venham
a ocupar as mencionadas áreas. Reconhecia o modo
de vida dos seringueiros e denominava a modalidade
"assentamento" por não existir outra forma de reconhe-
cimento no arcabouço legal disponível da reforma agrária
(Allegretti, 2008, p. 47).

No entanto, foram diversas dificuldades políticas encontradas na implementação da reforma agrária no cenário político nacional da década de 1980, bandeira sempre impedida de se realizar devido, principalmente, ao passado colonial brasileiro. Soma-se, ainda, o projeto econômico que incluía o protecionismo da borracha, porém o baixo valor do látex no mercado mundial, dando lugar aos sintéticos hidrocarbonados, fez com que o movimento seringueiro se aproximasse mais da questão ambiental como estratégia de luta (Cunha, 2010; Almeida, 2004), identificando-se, ressignificando as bandeiras ambientalistas e dialogando com o estabelecido no ideário do "desenvolvimento sustentável”. O antropólogo Mauro Almeida (2004) conta-nos ainda que essa articulação do movimento seringueiro e ambientalista conectou a floresta e seus povos a uma rede nacional e internacional, e foi capaz de dar respostas concretas às questões locais e regionais da Amazônia, que envolvem "uma reavaliação do significado da terra, dos limites do sindicalismo e da complexidade dos regimes de
propriedade"(Almeida, 2004, p. 48). O movimento seringueiro, por meio do Conselho Nacional dos Seringueiros - CNS -, passa a contar com o apoio de partidos políticos, ONGs e fundos nacionais e internacionais para financiar suas ações, possibilitando aos seringueiros ampliar o campo de suas ações e sua força política.

A aliança conservacionista entre seringueiros e ambientalistas foi fundamental para que na Constituição de 1988, em seu artigo 225, inciso 3. ${ }^{\circ}$, no capítulo destinado ao Meio Ambiente, fosse determinada a criação de territórios reconhecidos pelo poder público, a partir de uma abordagem ambiental que, em conjunto com a Lei 7.804, de 24.07.1989, compatibilizou a Política Nacional de Meio Ambiente com os dispositivos constitucionais de 1988, incluiu também a categoria das reservas extrativistas como um espaço territorial especialmente protegido.

Em janeiro de 1990, o Decreto-Lei n. ${ }^{\circ} 98.897$ normatiza essa categoria de ordenamento de território, viabilizando em termos formais a criação da Reserva Extrativista do Alto Juruá, e em seguida as Reservas Extrativistas Chico Mendes, Rio Cajari e Rio Ouro Preto, todas no território acreano. A implementação dessas hoje chamadas Unidades de Conservação, representa uma grande vitória para os seringueiros, cuja identidade, práticas culturais e cosmologias passam a ser reconhecidas pelo Estado, ficando formalmente garantido o direito coletivo da terra.

Acreditamos aqui que autonomia reivindicada pelos seringueiros em seu território foi parcialmente contemplada em diversos aspectos dispostos no Decreto Lei n. ${ }^{\circ}$ 98.897/90, a concepção de espaços territoriais e exploração autossustentável adotada nele. "[...] configura uma territorialidade identificada a uma população destinatária cujas práticas e os 
saberes caracterizam uma matriz de racionalidade que implica na manipulação da produtividade da natureza" (Porto-Gonçalves, 2003, p. 560).

A Concessão do Direito Real de Uso, doravante no texto CCDRU, é o instrumento de regularização fundiária, previsto no Decreto-Lei n. ${ }^{\circ}$ 271, de 1967, que se aplica aos casos em que o poder público transfere a posse de um imóvel público para particulares, que ficam assim autorizados a utilizar ou explorar a área para fins de interesse social. Contudo, tradicionalmente, os contratos firmados pelo Estado brasileiro, na maior parte das vezes, garantiam a apropriação de territórios para fins privados, cuja lógica de expropriação remonta a uma racionalidade instrumental de Estado, alicerçada na colonialidade. De acordo com o Decreto-Lei de 1967, que ordenava loteamentos urbanos, e que o Decreto de 1990 se refere quanto ao CCDRU, lê-se no seu artigo $7 .^{\circ}$, cuja redação só foi alterada em 2007, a noção de interesse social dada pelos seringueiros era de outra ordem que a prescrita:

Art $7^{\circ}$ É instituída a concessão de uso de terrenos públicos ou particulares, remunerada ou gratuita, por tempo certo ou indeterminado, como direito real resolúvel, para fins específicos de urbanização, industrialização, edificação, cultivo da terra, ou outra utilização de interêsse social (Brasil, 1967).

Nesse momento, o enquadramento e ordenamento das reservas extrativistas via CCDRU indicou uma virada de mesa. Na proposta seringueira, o Estado deveria garantir, num modelo de concessão de uso de terrenos públicos, a proteção do ambiente, principalmente contra interesses madeiros e pecuaristas, a permanência das populações no seu território de origem e sua reprodução social, além de observar o cumprimento de regras estabelecidas autônoma e coletivamente pelos extrativistas, sem impor sua cartilha colonial, baseada na tutela de espaços e pessoas.

A perspectiva de análise de um movimento intelectual que sustenta que há ainda vigente um modelo de colonialidade, arcabouço do próprio projeto de modernidade, eurocêntrico, pautado nas divisões de gênero e raça, que organiza a vida, o saber e o poder nos Estados nacionais do Hemisfério Sul, em particular nas Américas, ajudam-nos a compreender as formas de participação e autonomia de grupos sociais marginalizados. Autores dos chamados estudos decoloniais permitem-nos empreender uma análise em duas partes. Em primeiro lugar, o movimento seringueiro com suas conquistas ilustra aquilo que Santos \& Avritzer (2002) indicaram como possibilidade de emancipação nos processos de deliberação numa corrente contra-hegemônica do modelo analítico de Estado e democracia, desde os contratualistas, a de Shumpeter, a poliarquia de Dahl e a ação comunicativa habermasiana ${ }^{7}$. Em segundo, a proposta erigida no seio do movimento seringueiro ilustra uma perspectiva radical que parte de baixo para cima e que impõe ao Estado a revisar seu papel histórico e recepcionar as demandas e reinvindicações advindas da luta de um movimento social popular. Nesse sentido, a institucionalização daquelas demandas deveria apontar para a emancipação, conforme descrevem os autores, na medida em que passam a fazer parte do arcabouço conceitual e procedural do Estado. Segundo os autores:

Trata-se de negar as concepções substantivas de razão e as formas homogeneizadoras de organização da sociedade, reconhecendo a pluralidade humana. No entanto

${ }^{7}$ Para o assunto, ver Souza (2014). Não é nosso objetivo fazer uma revisão por que passou o conceito de participação social na Ciência Política, mas compreender como ocorre a participação nos processos decisórios da Resex no sentido da emancipação e autonomia dos extrativistas. 
o reconhecimento da pluralidade humana se dá não a partir da suspensão da ideia de bem comum [...], mas a partir de dois critérios distintos: a ênfase na criação de uma nova gramática social e cultural e o entendimento da inovação social articulada com a inovação institucional, isto é, com a procura de uma nova institucionalidade da democracia (Santos \& Arvitzer, 2002, p. 15-16).

As conquistas acumuladas pelo movimento seringueiro ao serem institucionalizadas alude para a permeabilidade do Estado na incorporação de demandas e de cosmologias dos diferentes grupos sociais. Essa incorporação parece ter figurado, sob uma racionalidade instrumental, em uma atualização do sentido colonizador do papel do Estado na medida em que replica a adequação tecnoburocrática de uniformização dos contextos locais a uma padronização universal. Tal padronização, defendemos, ao invés de incluir na agenda de Estado interesses e demandas das minorias, as submete à mesma gramática que o movimento seringueiro teimou em superar. O processo de apropriação pelo Estado da invenção da Resex define-se mais tarde na Lei 9.985/2000, do Sistema Nacional de Unidades de Conservação, conhecida por Snuc, na qual esses territórios passam a ser considerados Unidades de Conservação e sua gestão vai distanciar-se ainda mais da perspectiva autônoma e autogestionária proposta pelos seringueiros, aproximando-se da ideia de participação social difundida a partir da reorganização da gestão pública ocorrida no Brasil na década de 1990 (Milani, 2008).

Em tese, a ideia da participação social deveria promover uma renovação política, ampliando o processo democrático na formulação de políticas públicas e na mediação de conflitos. No entanto, tais processos vêm se mostrando de forma diferente da perspectiva de uma teoria-ação contra-hegemônica da democracia, na forma com que foi edificado pelos movimentos sociais na década de 1980 e 1990 , que lutaram para inserção de uma prática política mais ampla e autônoma. A maneira como a participação vem sendo implementada no Brasil, no caso das políticas públicas de Unidades de Conservação de Uso Sustentável, promove, segundo nossa análise, a interferência de outros agentes na orientação das ações coletivas locais que influenciam, dominam, controlam e padronizam as decisões e as ações (Dagnino, 2004; Sayago, 2008), do que propriamente proporcionam a construção de uma normatividade pós-colonial para uma nova gramática democrática. Os espaços de participação acabam por funcionar como um reforço ao controle e poder do Estado a serviço do capital, gerando a falsa impressão que há partilha do poder decisório.

Para Ballestrin (2014), o modelo de democracia brasileiro segue orientado pelos modelos hegemônicos de democracia dos países centrais e os modos de participação então implementados favorecem experiências de uma abertura às demandas compostas por identidades, sem, entretanto, emancipá-las de sua condição subalterna. De acordo com Souza (2014), o modelo contemporâneo de democracia tem justamente dificuldades em propiciar a participação em condições de desigualdade em diversos níveis.

Dessa forma, garantir a criação de canais ou espaços de participação não significa necessariamente ampliar a participação democrática. Principalmente quando esses espaços são orientados por modelos provenientes de manuais elaborados por agências internacionais ${ }^{8}$, pelas instituições governamentais, como no caso da gestão de Unidades de Conservação - UCs -, há uma tendência em se reproduzir nesses espaços de participação as desigualdades 
já encontradas nas localidades, a cultura política local, o patrimonialismo, o clientelismo político marcante do estado brasileiro, tal como o conceitua a teoria social brasileira. Além disso, os modelos incorporados de participação tendem a escamotear as diversas forças e poderes e, principalmente por terem suas ferramentas, metodologias e todo um vocabulário construído fora das características específicas das localidades, inclinam-se a subjugar a capacidade de formulações críticas e estratégias de ação emancipatórias.

No caso das reservas extrativistas, o que se vê na sua institucionalização por meio do Snuc é a retirada de seu potencial transformador, delegando ao Estado o poder de definir a maneira mais "adequada" de garantir a representação dos diferentes interesses sociais na gestão do território. De acordo com Boaventura de Sousa Santos \& Leonardo Avritzer (2002), os processos de descolonização e de democratização, objetos de intensa disputa política, por alvejarem interesses e concepções hegemônicas, muitas vezes são suprimidos e descaracterizados por via da cooptação ou da integração, apontando principalmente para a fragilidade institucionalizante da participação, como demonstra os autores ao analisarem processos participativos em Portugal, na Colômbia, Moçambique e no Brasil.

A partir do Snuc, a gestão das reservas extrativistas passa a ser realizada a partir de um conselho deliberativo, presidido pelo órgão responsável por sua administração, o ICMBio, e constituído por representantes de órgãos públicos, de organizações da sociedade civil e das representações das populações tradicionais residentes no território. Os conselhos são entendidos na gestão ambiental brasileira como fóruns ou espaços de discussão, negociação e gestão das Unidades de Conservação e de sua área de influência para tratar de questões ambientais, sociais, econômicas, culturais e políticas (ICMBio, 2015). A participação nesse caso é feita por meio da deliberação, em que os representantes das entidades arbitram as políticas adotadas na gestão da UC. Todas as deliberações e encaminhamentos resultantes desses espaços são recebidas e analisadas pela Advocacia Geral da União - AGU - por meio das Procuradorias Gerais Especializadas - PGE -, onde se define se as propostas estão em conformidade com a legislação e poderão ser postas em prática, ou então se justificam os motivos pelos quais a UC não poderá implementá-las. Há, portanto, limites impostos pela submissão das regras que nem sempre são acomodadas às "conformidades" legais, indicando restrições de outra ordem, no mais das vezes, realizando o exercício da tutela às comunidades ditas tradicionais.

A mudança de concepção instaurada a partir da obrigatoriedade da instituição dos Conselhos Deliberativos, prevista pelo Snuc, na gestão das reservas extrativistas, contrapõe-se à forma com que elas foram originalmente concebidas e defendidas como demonstrado inicialmente neste artigo. Nesse sentido, nossa análise leva a crer que o Snuc, ao criar o Conselho Deliberativo, retira a centralidade e autonomia da gestão da Resex das mãos da população extrativista de duas formas: a) centralizando a gestão pelo poder público por meio da orientação legal da presidência do conselho que

\footnotetext{
${ }^{8}$ Para o assunto, ver Araújo (2017). A autora, em sua análise, relaciona a assimilação dos conteúdos e orientações dos manuais de agências internacionais como o Banco Interamericano de Desenvolvimentos (BID), GIZ (cooperação alemã), Global Enviroment Facility (GEF), Agencia de Cooperação Internacional Japonesa (Jica), Programa das Nações Unidas para o desenvolvimento (Pnud), às políticas públicas de Meio Ambiente no Brasil, nas quais a participação social é limitada às diretrizes que incluem gestão, avaliação, metodologias e resultados de projetos, e sem as quais não ocorre o financiamento.
} 
investe o agente de estado na condução dos processos; e a outra, b) dando poder de voto a agentes que representam outros objetivos no território, àqueles relacionados à racionalidade de exploração econômica monopolista. No primeiro pressuposto, a orientação da presidência, por sua vez, invoca duas inferências: à presidência cabe o poder de decisão da pauta, à condução dos processos e estabelecimento de prioridades, e à questão da representatividade. $\mathrm{O}$ fato de não haver rotatividade da presidência, e essa se fazer sempre por meio do agente de estado, desloca o protagonismo das representações extrativistas. Como corolário à manipulação da pauta do conselho, que dependerá da correlação de forças presentes na composição de tal fórum, impossibilita a apropriação da gramática do Estado pelos grupos sociais, uma vez que a expertise técnico-burocrática pode ser utilizada para exercer a tutela do Estado a esses grupos, induzindo-os a abandonarem suas pautas por "imposições legais". No que diz respeito à representatividade, quando a delegação da UC é exigida para fora do âmbito da Resex, paira a suspeição de qual representação efetivamente se configura. É o Estado na qualidade de mediador de conflitos e, portanto, o intérprete de uma coadunação de vertentes de interesses desiguais e assimétricos? É porta-voz dos extrativistas e suas práticas ou das demandas de desenvolvimento econômico local sob a lógica da exploração do trabalho?

Entendemos que houve um deslocamento e burocratização da condução dos processos de ordenamento e resolução de conflitos, de uma estrutura que expedia as determinações de forma horizontal, entregando o poder de decisão à figura da Associação-Mãe. Essa entidade congregava tipos específicos de representação de acordo com a organização dos próprios extrativistas, respeitando, de certa forma, suas diferenças internas. $\mathrm{O}$ CCDRU concedido à Associação-Mãe firmava-se como canal de comunicação das requisições dos grupos sociais com vistas ao reconhecimento do Estado. Com a edição do Snuc, uma estrutura hierarquizante é prescrita e a Associação-Mãe perde sua função gregária, fazendo desaparecer ou aspergindo o próprio CCDRU. Nesse modelo, sob o argumento da simetria entre agentes e interesses, os agora chamados beneficiários (ICMBio, 2013) devem compor a maioria das cadeiras do Conselho Deliberativo (ICMBio, 2007) ${ }^{9}$, contudo a maioria extrativista, per se, não garante a vocalização do movimento social por duas razões principais. Em primeiro lugar, as condições de representação no Conselho nem sempre se conectam com a representação comunitária ou de classe, pois as escolhas respeitam a circunstâncias políticas cuja justificação responde muito mais às grafias e apropriações de um vocabulário técnico ambiental por parte de lideranças, que podem ou não acumular acordos sobre sua legitimidade. Em segundo, na medida em que as lideranças se fixam nas cadeiras e assumem responsabilidades na agenda do Estado, a conexão com sua base representativa vai se tornando cada vez mais tênue e esgarçada, transmutando interesses coletivos em favor dos individuais. Esse distanciamento permite que a atuação de empreendedores sociais seja condicionada às potências de uma racionalidade econômica explotadora, que acaba garantindo sua hegemonia no interior do Conselho Deliberativo, ao menos naquele que nos debruçamos, qual seja, da Resex Marinha de Arraial do Cabo.

\footnotetext{
${ }^{9}$ A Instrução Normativa (IN) n. ${ }^{\circ}$ 2, de 18 de setembro de 2007, disciplina as diretrizes, normas e procedimentos para a formação e funcionamento do Conselho Deliberativo de Reserva Extrativista e de Reserva de Desenvolvimento Sustentável e em seu artigo $9 .^{\circ}$, III prevê que deverá ser garantida maioria de representantes das populações tradicionais na composição do conselho.
} 


\section{Reserva Extrativista Marinha do Arraial do Cabo e a aplicação dos instrumentos de gestão sob uma racionalidade moderna/ colonial $^{10}$}

A criação da Resex-Mar de Arraial do Cabo, em janeiro de 1997, ampliou a aplicação do conceito de reserva extrativista construído na luta dos seringueiros ao ambiente marinho, uma vez que, até 1994, esse tipo de território só havia sido implementado em ecossistemas florestais na Amazônia (Spínola, 2012, p. 17). A Resex-Mar Arraial do Cabo, foi a segunda Resex da modalidade marinha criada no Brasil. De acordo com o parecer do Centro Nacional de Populações Tradicionais $-\mathrm{CNPT}^{11}$ no processo de criação da Resex Marinha de Arraial do Cabo, a unidade foi instituída para proteger as áreas de pesca utilizada por populações tradicionais que viviam há gerações do extrativismo dos recursos pesqueiros do município de Arraial do Cabo, litoral do Rio de Janeiro. Visava, principalmente, a proteger as áreas de pesca de canoa da ação de traineiras e arrastões, provenientes de outros estados, que utilizavam barcos motorizados e petrechos mais sofisticados, possibilitando a pesca em larga escala e causando grande impacto ambiental nas áreas próximas aos costões, áreas essas utilizadas tradicionalmente pelos extrativistas.

Por orientação do CNPT, em 1997, foi criada a Associação da Reserva Extrativista Marinha de Arraial do Cabo (Aremac), na qualidade de "Associação-Mãe", que tinha como objetivo congregar os pescadores das diferentes artes de pesca para gerir a Resex e elaborar o seu Plano de Utilização. Para se associar à Aremac era necessário ser pescador, residente em Arraial por 10 anos e votar no município há pelo menos cinco anos. Cabe ressaltar aqui que o sentido de pertencimento na elaboração identitária do pescador artesanal da localidade engloba diversas dimensões e aspectos, mas inclui a identidade "cabista", designação nativa para o "nascido e criado" em Arraial do Cabo. Tal categoria êmica gera uma miríade de implicações para a gestão da unidade, já que não são as práticas sociais e econômicas que estão em relevo, mas tão somente a circunscrição político-administrativa do cidadão de Arraial do Cabo. Assim, é curioso incluir na categorização a obrigatoriedade de ser eleitor no município, o que pode apontar para um entrecruzamento deveras explícito da política partidária local para dentro da Resex.

As assembleias dos pescadores da Aremac não diferiam muito das assembleias sindicais, sendo a mesa composta pela diretoria da Associação e pelo diretor da Resex (funcionário do Ibama). Os pescadores agrupavam-se por arte de pesca e suas respectivas praias de atuação. O sistema de votação era aberto e feito pelos pescadores com os braços levantados. Apesar de participarem da assembleia, os representantes das operadoras do turismo não podiam votar por não serem considerados pescadores/ extrativistas, o que gerava um tensionamento. Atualmente, desde a definição do Perfil do Beneficiário, elaborado pelo ICMBio na Resex-Mar Arraial do Cabo, no ano de 2014, os operadores de turismo têm sido enquadrados como beneficiários, numa

\footnotetext{
${ }^{10}$ A análise aqui descrita é oriunda de uma pesquisa de campo para a feitura de um Trabalho de Conclusão de Curso da linha de pesquisa "Populações Costeiras" do Curso de Especialização em Ciências Ambientais em Áreas Costeiras, do Instituto Federal do Rio de Janeiro, Campus Arraial do Cabo.

${ }^{11}$ Parecer CNPT - 016/1995 inserido no processo: 02001.002396/95-25, que trata da criação da Reserva Extrativista de Arraial do Cabo.
} 
classificação que atenua os limites da distinção beneficiário/usuário. Havia também os representantes da Capitania dos Portos, que disputavam com os pescadores/extrativistas a soberania na tomada de decisões sobre a utilização do espaço marítimo (Lobão, 2010). Relatos de analistas ambientais do ICMBio apontam que, mesmo nesse formato, já havia problemas de legitimidade e formação de grupos de interesse que ditavam as pautas, e que, entre os anos de 2009 e 2010, poucas assembleias de pescadores foram realizadas, havendo um grupo mais ou menos fixo de lideranças da pesca que decidia junto ao ICMBio as regras que orientavam o uso do território. Lobão (2010) aponta, no entanto, que a cogestão da Resex-Mar Arraial do Cabo com a Aremac vinha se organizando gradativamente, e, até 2005, subordinava toda a atividade de turismo marinho realizada na unidade, aos interesses da pesca artesanal. A grande mudança nesse cenário veio com a decisão do Ibama em instituir uma taxa de visitação que "fez com que os conflitos internos crescessem exponencialmente" (Lobão, 2011, p. 206).

Adiante cotejamos excertos das falas de nossos interlocutores para subdividir esta seção como recurso de organização textual, focando nos instrumentos de gestão. Tal interlocução foi garantida a partir da participação do autor na representação no Conselho Deliberativo da Resex Arraial do Cabo, na sua relação com os membros do conselho, e no esforço da pesquisa de campo da autora entre 20162017. São trechos de falas nas reuniões ordinárias do Conselho Deliberativo da Resex nesse período. A pesquisa de campo privilegiou extrativistas, usuários, membros de outras instituições e analistas

\footnotetext{
${ }^{12}$ Os nomes foram suprimidos para garantir o anonimato das pessoas.
}

ambientais do ICMBio, representantes de entidades e de organizações governamentais e não governamentais da composição do Conselho Deliberativo. A reflexão realizada doravante alberga apenas o universo da Resex Arraial do Cabo, opção metodológica que favorece uma análise microssociológica mais aprofundada das dinâmicas sociopolíticas no interior da UC.

\section{1. "O CCDRU não trouxe beneficio, é só olhar o píer lotado de barco de turismo"}

pescador de Arraial $^{12}$

Apesar da criação da Resex, em 1997, e da Associação da Reserva Extrativista de Arraial do Cabo, no mesmo ano, a CCDRU só foi concedida em 2010 após algumas reuniões realizadas pelo ICMBio para a divulgação da minuta do contrato. Maranhão (2012) aponta-nos, em sua dissertação, que a discussão sobre esse instrumento não foi muito aprofundada nas bases, como também não houve ampla divulgação do significado e das implicações que o instrumento traria para a Resex-Mar Arraial do Cabo e para os extrativistas. As discussões concentraram-se entre o ICMBio e a Aremac, que alardeava nas reuniões sua predestinação para receber a concessão, justificando que a entidade havia sido criada exatamente com esse intuito e já contava com infraestrutura e equipamentos, tais como lancha, sede e mobiliário necessários para assumir tal encargo. Assim, a possibilidade de candidatura de outras associações ao status de concessionária foi pouco difundida, mas chamou atenção de alguns pescadores presentes nas reuniões. Ainda segundo a autora, as reuniões apresentavam uma urgência em encaminhar a assinatura do contrato de concessão 
por ocasião do aniversário de 3 anos do ICMBio, por haver uma meta institucional em celebrar o contrato dessas unidades, já indicada pela Portaria Interministerial n. ${ }^{\circ}$ 436, de 2 de dezembro de 2009 , como também em função de facilitar os investimentos provenientes do programa Parques da Copa, na estruturação do uso público de determinadas Unidades de Conservação para o fluxo turístico previsto na realização da Copa do Mundo da Fifa no Brasil, em 2014. A CCDRU seria assim o pontapé inicial para implementar as mudanças propostas pelo Snuc, como o Plano de Manejo, Conselho Deliberativo e o cadastramento dos beneficiários, invertendo toda ideia inicial contida na celebração de um contrato de gestão que permitiria que os extrativistas assumissem autonomamente o controle dessas áreas. Ao final desse processo, a Aremac obteve o voto da maioria das entidades de pesca que, na ocasião, já compunham a chamada "articulação do Conselho Deliberativo” (Maranhão, 2012). Tal apontamento indica que a articulação para assinatura do CCDRU obedeceu a uma ordem de fatores que não incluiu necessariamente um movimento orientado pelas necessidades e demandas dos extrativistas de Arraial do Cabo. Ao contrário, segundo a ótica da crítica decolonial, pode-se inferir que a lógica instrumental do estado moderno, subjuga e subalterniza as formas de resolução de conflitos, os saberes e os modos de apropriação do território por parte das elaborações da população tradicional, e elege, em seu turno, a desapropriação desses saberes e práticas como condição de participação do processo civilizatório promovido pelo próprio estado, a chamada cogestão. A cogestão, no exercício do poder de decisão, sob a pecha do compartilhamento, submete os saberes e práticas ditos tradicionais a uma "violência epistêmica" (Castro-Gomez, 2005), na medida em que invisibiliza o outro, na sua perspectiva de autorrepresentação. No ofício da Associação Conselho de Pesca, protocolado em 2016, seis anos após a criação do Conselho Deliberativo e entrega do CCDRU, lê-se: "Até o presente momento os beneficiários jamais foram esclarecidos acerca da natureza jurídica do CCDRU, sequer para que finalidade deveria ser outorgado, encontrando-se "vendidos" e "leigos" no assunto".

É de se notar que a indeterminação conceitual do instrumento citado permite hermenêuticas distintas e, consequentemente, outorga o poder de enunciação à resultante da correlação de forças no interior do Conselho Deliberativo, que, no caso da Resex-Mar Arraial do Cabo, favorece à acumulação de capital como se verá seguir.

\section{2. "São pescadores mesmos que querem} retirar a CCDRU da Aremac ou é somente o representante que está decidindo?"

liderança da Confrem

Em 2016, a Associação Conselho da Pesca protocolou um pedido junto à Resex-Mar Arraial do Cabo solicitando o destrato do CCDRU, alegando que a Aremac, enquanto concessionária, vem quebrando o contrato firmado. $\mathrm{O}$ pedido resultou na criação de um Grupo de Trabalho sobre a CCDRU que tinha entre seus integrantes os representantes da pesca e, em peso, da Associação Conselho da Pesca. Ao final de 2017, quando o tema foi levado à votação em reunião do Conselho Deliberativo, diversas foram as falas que levantaram a questão da legitimidade das representações e das associações e sobre o desconhecimento, por parte do pescador, 
do que se trata realmente a tal da CCDRU. O tema foi levado à votação sem o aprofundamento das discussões para além do Conselho Deliberativo, ou seja, sem ampliar esse debate, haja vista que interfere de modo direto na representação de todos os pescadores de Arraial do Cabo. O resultado foi que a proposta de destrato ganhou com o placar de 16 votos a favor (representantes das associações de pesca), quatro votos contrários e uma abstenção. O representante da Confederação das Reservas Extrativistas Marinhas - Confrem -, liderança em escala nacional presente à reunião, enfatizou o risco que a retirada da CCDRU representa para Resex de Arraial do Cabo no atual momento político vivido no Brasil, caracterizado pela perda de garantias e direitos sociais. A liderança relembrou a importância da luta e conquistas do movimento seringueiro, apontando inclusive que a retirada da CCDRU implicaria na perda dos benefícios concedidos pelo Incra aos beneficiários $\mathrm{A}$ e $\mathrm{B}^{13}$.

O Grupo da Pesca foi formado inicialmente por representantes das associações de pesca para que pudessem alinhar suas demandas e posicionamentos diante dos outros agentes nas ações propostas pelo Conselho Deliberativo (Revisão do Plano de Utilização, Acordo de Gestão, Perfil do Beneficiário e Ordenamento do Turismo Náutico). No entanto, em função de seu Regimento Interno, que, segundo relatos, não vem sendo seguido, e que aponta a necessidade de as associações indicarem novas representações a cada dois anos, esse grupo desenvolveu um interesse específico que se materializou na criação de mais uma associação com a nomenclatura Associação Conselho da Pesca. Observamos nas reuniões do Conselho Deliberativo e que a própria nomenclatura vem condicionando outros participantes a crer que tal grupo possui uma posição diferenciada, um "Conselho dentro de um Conselho", no interior da estrutura de deliberação, e, por isso, causa certa confusão aos participantes sobre qual "Conselho" se faz referência durante as discussões.

Apesar da Associação Conselho da Pesca não ter uma cadeira nominal específica no Conselho Deliberativo, todos os seus membros possuem assento como representantes de outras entidades ligadas à pesca. Levando em consideração que a Associação Conselho de Pesca aglutina os 16 votos entre os 29 votos totais das representações de todo universo do Conselho Deliberativo atualmente, nas reuniões dos anos de 2016 e 2017, por ocasião de votações decisivas, o Conselho da Pesca votou em bloco, emplacando vitórias que não necessariamente fortalecem os extrativistas. Como exemplo as lideranças agregadas na Associação Conselho da Pesca votaram a favor de manter mais de uma embarcação de turismo por beneficiário, indo contra a ideia de que cada beneficiário deveria possuir apenas uma autorização de operação, permitindo ampliar o acesso a outras pessoas, geralmente de sua rede de relações, para que pudessem ser autorizados a operar no turismo náutico. Também votaram a favor para que as grandes embarcações operassem com 120 passageiros quando anteriormente já havia sido decidido fervorosamente que a capacidade máxima por embarcação seria de 80 pessoas. Tal limite tem por intuito regular que todos os barcos tenham passageiros suficientes para a viabilidade econômica da atividade na fase da baixa temporada e, dessa forma, minimizaria o impacto sobre o ambiente e sobre

\footnotetext{
${ }^{13}$ Tais categorias foram elaboradas para desenhar o Perfil do Beneficiário em 2014, isto é, aquele a que se destinam as políticas da Resex. A categorização será explicitada adiante.
} 
a prática da pesca gerado pela visitação. Nessas reuniões, vários representantes e participantes da reunião sugeriram que as vitórias obtidas haviam sido fruto da bolsa nada a opor que se referia a uma suposta compra de votos dos representantes da Pesca pelas Associações de Turismo. A bolsa nada a opor, segundo relatos, é o valor repassado pelas associações de turismo a lideranças para garantir $\mathrm{o}$ apoio às demandas e interesses daquele grupo.

O formato da Associação Conselho da Pesca pretende substituir a Aremac como aglutinadora de extrativistas, aproximando-se da ideia de Associação-Mãe vinculada ao início das Resex, ainda sob o direcionamento do Decreto n. ${ }^{\circ}$ 98.897, de 1990. Em sua proposição inicial, a Associação Conselho da Pesca agrega os representantes das outras associações de pesca a fim de fortalecer os interesses dos pescadores, uma vez que se avalia que a Aremac hoje já não cumpre esse papel. No entanto, a Associação Conselho da Pesca não apresenta propostas que indiquem que haja vínculos com as bases. Pelo contrário, como demonstrou a votação da última portaria do turismo náutico, quando a temática da restrição de "um barco por beneficiário" foi pautada, os membros do Conselho da Pesca demonstraram atuar em função dos interesses não mais da pesca em si, mas com vistas à manutenção de autorizações e novas autorizações para operarem seus barcos de turismo, uma vez que, apesar de se identificarem como pescadores, muitos atuam também no turismo, sem contar os bônus da bolsa nada a opor, conforme relatado acima. Como são esses mesmos representantes partícipes da deliberação para a emissão de autorizações do turismo, caso a caso, muitas vezes abandonam os critérios criados pelo Conselho Deliberativo para emissão de autorizações, e atuam sob critérios da pessoalidade, desautorizando eventuais concorrentes e/ou adversários pessoais ou do grupo. O ICMBio acata a demanda, apesar de perceber a contradição na polêmica. Aqui, com ajuda de Maldonado Torres (2007), compreendemos que o processo de apropriação capitalista alcança aqueles espaços que supostamente teriam sido reservados, pela força dos movimentos sociais, a um outro regime econômico que não se baseia imediatamente na acumulação de capital, como queria o movimento social que pretendia defender a pesca em Arraial do Cabo. No nosso enfoque, é o próprio estado por meio de seus agentes que, não apenas permite a distorção dos objetivos iniciais da proposta extrativista, mas o referenda na colonialidade do poder econômico moderno que, por sua vez, engendra uma colonialidade do ser, cujo alcance atinge e submete as lideranças extrativistas em Arraial do Cabo na Associação Conselho da Pesca, credenciadas a comunicar sua distintividade política, cultural e econômica, à lógica de acumulação.

\section{3. "O pescador tem que fazer o dever de casa"}

chefe da Resex Arraial do Cabo

O Conselho Deliberativo da Reserva Extrativista Marinha de Arraial do Cabo -foi criado formalmente pela Portaria n..$^{\circ} 77$, de agosto de 2010, 13 anos após a criação da UC, a fim de instaurar o modelo de participação social preconizado pelo Snuc para as UCs de Uso Sustentável. O Conselho Deliberativo é formado por instituições interessadas em participar da gestão da Resex-Mar AC, e essas devem indicar seus representantes para participarem das reuniões mensais, extraordinárias, Grupos de Trabalho e Câmaras Técnicas propostas nesse fórum. Cabe ao Conselho Deliberativo, de 
acordo com regulamentos, decidir sobre assuntos relacionados à forma de seu funcionamento, a partir da elaboração do Regimento Interno, decidir sobre o conteúdo do Plano de Ação do Conselho, emitir recomendações e moções, deliberar sobre assuntos relacionados à gestão da $\mathrm{UC}$, emitir resoluções, homologar o perfil e a relação das famílias beneficiárias da UC, estimular o protagonismo e o fortalecimento das organizações comunitárias e aprovar, por meio de resolução, o Acordo de Gestão e o Plano de Manejo Participativo da Unidade.

Atualmente participam do conselho 27 instituições, distribuídas em diferentes setores, como explicitado anteriormente. Apesar do grande número de instituições, grande parte delas frequenta eventualmente as reuniões. Na última reunião do Conselho Deliberativo, antes da redação deste texto, realizada em março de 2018, uma das pautas travadas foi a da renovação das entidades no conselho, o que suscitou diversos questionamentos por parte dos presentes. $\mathrm{O}$ primeiro tensionamento diz respeito à representatividade das lideranças de pesca, que vem sendo questionada copiosamente nas plenárias das reuniões. Seriam mesmo os representantes da pesca pescadores? Tal questionamento é baseado no fato de que a maioria dos representantes da pesca possuem barcos de passeio náutico e, ainda, aprestam suas embarcações a terceiros, que não necessariamente são beneficiários da Resex. Essa reflexão aponta para algumas análises as quais não prologaremos aqui, mas que devem ser pontuadas. Ao ser indicado como representante da pesca no âmbito de atuação do Conselho Deliberativo, automaticamente esse representante é considerado beneficiário $\mathrm{A}$ e, dentre outros arbítrios, são esses atores que irão deliberar sobre quem tem o direito de receber as autorizações para atuar no turismo náutico, o que acaba gerando resoluções em causa própria e distante dos interesses dos pescadores, aos quais formalmente representam. Tal questão coloca em xeque a legitimidade das representações também na isenção desses representantes ao deliberarem sobre as regras do ordenamento do turismo náutico. Outra questão levantada é o número de associados vinculados às associações que têm cadeira no Conselho Deliberativo. Existem associações que contam com muitos associados e outras que tem apenas dois ou três associados, fato que vem gerando discussões também quanto à escala de representação, os interesses dos representantes e o papel das associações.

Segundo a Portaria n. ${ }^{\circ}$ 5, de janeiro de 2016, art. $2 .^{\circ}$, incisos VI, VII e VIII, é considerado beneficiário "A" pescador de família extrativista tradicional e morador de Arraial do Cabo ou pescador que veio morar em Arraial do Cabo há mais de 20 anos que exerce a pesca rotineiramente, tendo nessa atividade sua principal renda, sem vínculo empregatício. Pode exercer também o turismo de base comunitária, ser aposentado pela pesca ou trabalhar também no beneficiamento do pescado. Também são reconhecidos nessa categoria mestres na arte de pesca, mas que por impedimentos relativos à idade ou saúde não desempenham mais as atividades pesqueiras rotineiramente. Há ainda duas classificações, o beneficiário categoria " $B$ " e "C"; "B" tem os mesmos critérios da "A", mas a pesca não figura mais como atividade principal, "podendo fazer turismo, ou ter outra atividade profissional". Já o beneficiário da categoria $\mathrm{C}$ também necessita estar vinculado à tradicionalidade comprovada pela moradia em Arraial do Cabo por 10 anos ou ser de família tradicional, "desenvolvendo atividades de lazer ou atuando no ramo do turismo". A portaria não explicita claramente como se caracteriza a tradicionalidade, promovendo indeterminações 
conceituais e abrindo espaço para interpretações múltiplas e, muitas vezes, ambíguas acerca dos critérios de inclusão e exclusão. Dessa forma, a própria categorização cria fissuras que podem favorecer o desvirtuamento da proposta inicial alicerçada na independência e autonomia. Estamos entendendo que a categorização substantiva o processo identitário, subjugando-o à colonialidade, já que circunscreve, controla e tutela a interação social, ao invés de permitir ressignificações e representações outras, se atentassem para a dimensão processual da identidade em fluxo contínuo. Santos et al. (2005), apresentando o livro 4 Semear outras soluções: os caminhos da biodiversidade e dos conhecimentos rivais, aduzem que

[...] o conceito de "conhecimento tradicional" remete para a presença de um sistema homogêneo de pensamento, encobrindo o fato de que os grupos sociais renovam seus conhecimentos constantemente em função de novas experiências e de novos desafios postos por circunstâncias históricas novas. A emergência do tradicional corresponde assim a uma "cristalização" do étnico (Santos et al., 2005, p. 32-33).

Uma fala de um pescador na Oficina de Revisão do Perfil do Beneficiário, realizada em abril de 2018, garante que a caracterização não condiz com os sentidos de pertencimento dos extrativistas de Arraial do Cabo:

Para nós não existe $A, B$ e $C$, o que existe é tradição, $e$ a reserva que foi criada para pescador e não para $A, B$ ou $C$. Nós nos reconhecemos como pescadores, sabendo quem é quem e, qual atividade cada um faz, é quem está no mar. Nós não nos classificamos como $A, B$ ou $C$, nós nos classificamos como pescador

\footnotetext{
${ }^{14}$ Orientado pela Instrução Normativa n. ${ }^{\circ}$ 29, de 2012, do ICMBio.
}

\section{4. "O Plano de Utilização era feito no} respeito, hoje criou coisas técnicas como se já não existisse."

pescador de Arraial

O Plano de Utilização da Resex Marinha Arraial do Cabo, de 1999, foi concebido pelos extrativistas e aprovado pelo Ibama, órgão responsável pela gestão das Unidades de Conservação à época, e tinha por objetivo servir de guia para que os extrativistas realizassem suas atividades dentro de critérios de sustentabilidade econômica, ecológica e social no território da Reserva Extrativista Marinha de Arraial do Cabo, cabendo ao órgão gestor Ibama supervisionar as áreas extrativistas e acompanhar o cumprimento das condições estipuladas coletivamente (MMA, 1999). Esse documento, na maior parte do seu conteúdo, estabelece o ordenamento das atividades extrativistas relativas à pesca e vincula responsabilidades e direitos à Aremac, que na época ainda não era formalmente a entidade detentora da Concessão de Direito Real de Uso. Ainda vigente, o Plano de Utilização foi considerado defasado frente ao desenvolvimento de outras atividades econômicas na localidade, principalmente o turismo náutico. Além disso, ocorreram mudanças na legislação ambiental e pesqueira, e por isso houve diversas propostas de alterações normativas resolvidas nas Assembleias de Pescadores e no Conselho Deliberativo ao longo do tempo, tanto para a pesca quanto para o turismo náutico. No entanto, tais alterações não foram formalmente incorporadas ao Plano de Utilização (MMA, 2011) e a insuficiência de memória institucional para a identificação das temáticas tratadas no período levou a gestão da Resex, oportunamente, a optar 
pela revisão do Plano de Utilização, a partir de um novo instrumento, o chamado Acordo de Gestão ${ }^{14}$.

A proposta metodológica do Acordo de Gestão, na condução do processo de revisão do Plano de Utilização, baseava-se na realização de oficinas de praias, realizadas nos espaços de reunião de pescadores ou seja, na praia, nos paióis, na Marina dos Pescadores, nos entrepostos de pesca, nos espaços de trabalho e de convívio social, o que segundo a atual gestão, propiciou o maior envolvimento dos pescadores artesanais nas discussões. Esse processo acabou evidenciando a contradição entre as propostas das lideranças de pesca, que atuam como representantes no Conselho Deliberativo e as propostas elaboradas dos pescadores artesanais nas Oficinas de Praia, uma vez que as propostas da praia não foram aceitas e consideradas legítimas pelos representantes quando foram levadas para dentro do Conselho Deliberativo.

$O$ Acordo de Gestão ainda não foi publicado, o que ocasionou a edição de quatro portarias para o ordenamento do turismo náutico na Resex. Essas portarias objetivaram estabelecer critérios e procedimentos para a autorização precária dos serviços de passeio náutico na Resex até que fosse finalmente publicado o Acordo de Gestão, e fosse elaborado um instrumento duradouro e robusto que derivasse de ampla discussão dos temas, o Plano de Manejo. Assim, a pauta do turismo vem ocupando grande parte das discussões no âmbito do Conselho Deliberativo.

Mais uma vez, a autonomia e autorrepresentação dos extrativistas vem sendo invisibilizada por uma gramática de Estado, imbuída de uma lógica colonial, na medida em que os espaços formalmente ampliados à participação e deliberação são apropriados pelo uso da força simbólica e econômica de outros interesses, que invariavelmente à dinâmica da administração pública é conveniente. Um outro evento que reafirma a colonialidade nos processos de gestão no interior da Resex-Mar Arraial do Cabo trata de um artigo do Acordo de Gestão, que se pretendeu participativo e que tinha como objetivo final a autonomia dos extrativistas sobre seu território e suas práticas, como se verá a seguir.

Em reunião do Conselho Deliberativo da Resex realizada em março de 2018, a discussão sobre o último artigo pendente para a finalização no Acordo de Gestão, que deve atualizar o Plano de Utilização de 1999, deixou explicitada a insatisfação dos pescadores com a falta de autonomia na interposição de condições ao uso de seu território, principalmente no que diz respeito às atividades do Porto do Forno que estão ligadas à logística do apoio off shore à extração de petróleo na Baia de Campos, e que são causadoras de grandes impactos na pesca. $\mathrm{O}$ artigo 91, construído pelos pescadores nas oficinas de elaboração do Acordo de Gestão, visa a resguardar a influência dos extrativistas na tomada de decisões, restringindo as atividades portuárias em favor do interesse dos pescadores. Segundo o disposto na minuta do Acordo de Gestão:

Art. 91 - As restrições para atividades Portuárias na Reserva Extrativista Marinha do Arraial do Cabo, poderão ser alteradas, por Resolução do Conselho Deliberativo, de acordo com evidencias de conflitos com atividades extrativistas tradicionais, resultados de trabalhos de pesquisa e programas de monitoramento (Minuta do Acordo de Gestão, apresentada na Reunião Ordinária do Conselho Deliberativo da Resex-mar Arraial do Cabo, em março de 2018).

De acordo com a atual chefe da Resex, ao introduzir o tema como pauta para votação, o parecer da PGE/AGU apontou a impossibilidade de manter 
nesse artigo o poder conferido a uma resolução do Conselho Deliberativo que pretende decidir sobre atividades portuárias, uma vez que quem realiza o licenciamento ambiental é o Ibama, e é desse órgão a discricionariedade de regulação daquelas atividades. Pela análise da Procuradoria, não é possível aprovar um texto que legisla na concorrência das autarquias. Ao mesmo tempo que a PGE/AGU e o ICMBio entendem que esse artigo extrapola o alcance de ingerência da Resex, para os pescadores a retirada do artigo representa a invalidação do Acordo de Gestão, como exposto na fala de uma das lideranças: "se isso não entrar no acordo tem que rasgar $\mathrm{o}$ acordo, assim como rasgaram a portaria do turismo". A fala faz referência também a outro instrumento que não vem refletindo as necessidades e a autonomia dos pescadores da região, mas sim as demandas do trade turístico.

O artigo 91 foi finalmente suprimido na reunião de maio de 2018 do Conselho Deliberativo, quando foi proposta sua exclusão mediante a revisão de outros itens constantes do Acordo de Gestão, que, é preciso ressaltar, fora elaborado exaustivamente nas Oficinas de Praia em quatro anos de intensa mobilização, entre os anos de 2014 e 2018. Em pouco mais de um quarto de hora, um "ajuste" entre a gestão do órgão e as lideranças extrativistas, retomaram a permissão do uso do sonar pelas embarcações maiores e motorizadas, as traineiras, restringidas desde o Plano de Utilização de 1998, assim como a revisão das sanções previstas diante do descumprimento das regras estabelecidas para a operação do passeio náutico.

Cabe ressaltar ainda que, segundo outro parecer da PGE/AGU de 2018, o Acordo de Gestão não é reconhecido como instrumento eficaz, por não haver base legal que o sustente, subjugando-o, então, ao
Plano de Manejo cuja atualização e metodologia baseiam-se nos modelos utilizados pelo National Park Service estadunidense.

\section{Considerações finais}

Como exposto, as reflexões sobre os instrumentos de gestão como mecanismo de poder indicam o funcionamento do controle e poder do Estado na sua função vetusta de garantir as exigências da acumulação de capital, gerando a falsa impressão que há partilha do poder decisório com novos dispositivos institucionais tripartites, como no caso o Conselhos Deliberativo da Resex-Mar Arraial do Cabo. O que ocorre, a rigor, demonstra uma instrumentalização da proposta inicial das reservas extrativistas, que considera, na superfície, uma suposta horizontalidade de deliberação, como subterfúgio para o exercício democrático. Sub-reptícia e gradativamente, os interesses hegemônicos da acumulação monopolista de capital, no caso da Resex de Arraial do Cabo, o turismo náutico, vêm impondo suas pautas e ganhando terreno para garantir sua agenda e controle do território.

Esse raciocínio prenuncia uma participação vinculada às características de uma democracia nos moldes liberais, em que a prioridade da acumulação do capital é evidenciada em detrimento da redistribuição social e, portanto, a participação deve ser limitada para que não haja inconvenientes que coloquem em risco a prioridade da acumulação (Boaventura \& Avritzer, 2012, p. 27).

Como corolário, a apropriação do Estado e do capital para fins de acumulação da proposta da Resex tende a servir como uma reserva de mercado, que tem bases em diretrizes de agências 
multilaterais nos ditames ocultos nos manuais de participação social, que por sua vez têm sido usados como base metodológica para o levantamento de significantes nas Unidades de Conservação de Uso Sustentável. De acordo com os dados compilados e examinados na Resex de Arraial do Cabo pelos autores, as ingerências do turismo náutico, ou antes, da forma com que a atividade é praticada no interior da Resex, tendo a concorrência assimétrica como regra geral, desloca a proposta inicial emancipatória à uma monopolização dos serviços de turismo para um número limitado de pessoas.

É mister concluir que, passados 30 anos da proposta dos seringueiros no interior do Acre, apesar de se configurar muitas vezes como uma "política de ressentimento" na sua aplicação (Lobão, 2010), ela ainda hoje mantém sua originalidade e radicalidade em termos de direitos territoriais e de aprofundamento da democracia como um projeto popular. Não obstante, nas reflexões aqui trazidas, re-existe ainda, na memória social de Arraial do Cabo, a Resex como ensinamento de uma vitória dos pescadores artesanais pela garantia e controle de seu território. A interlocução entre a racionalidade moderno-colonial pode ser superada por iniciativas de controle social autogestionado. O sociólogo peruano Anibal Quijano esclarece que o advento da contínua democratização no devir da modernidade relaciona-se a processos sociais, materiais e subjetivos que estão nos limites das relações de exploração e dominação. Segundo o autor, "O mercado é o mínimo, mas também o limite da possível igualdade social entre as pessoas" (Quijano, 2005, p. 235).

Nos textos consultados pelos autores do pensamento decolonial, muitas vezes indicam, a partir de experiências locais que perduram espaços para experiências dialógicas e, por assim dizer, sua interlocução aponta para contradições no processo de construção da própria crítica à racionalidade colonial em termos epistêmicos, políticos e de prática social. Em outras palavras, a proposta formulada pelos seringueiros, apesar de cooptada pelo estado e transmutada em um modelo universal para dirigir políticas a uma identidade englobante amalgamada no termo extrativista, e que pode ter sido contaminada, não necessariamente está consumada.

Dessa forma, entendemos que os espaços conquistados continuam em disputa, mas, numa relação dialógica, aquilo que insiste em subverter a originalidade e radicalidade inicial e esvaziar o conteúdo da reivindicação social nas margens do Estado falha ao permitir que os extrativistas possam firmar sua agenda. Queremos crer que tais brechas recuperam "estradas de seringa" e abrem alternativas para "novos empates".

\section{Referências}

Allegretti, M. H. A construção social de políticas ambientais: Chico Mendes e o movimento dos seringueiros. 2008. Desenvolvimento e meio ambiente, 18, 39-59, 2008. Disponível em: https://revistas.ufpr.br/made/article/view/13423

Almeida, M. W.; Pantoja, B.; Ciavatta, M. Justiça local nas reservas extrativistas. Raizes, 23(1-2), 27-41, 2004. Disponível em: http://revistas.ufcg.edu.br/raizes/

Araújo, V. P. A participação social na criação de regras para o ordenamento do turismo náutico na Reserva Extrativista marinha do Arraial do Cabo - RJ. Trabalho de Conclusão de Curso (Ciências ambientais em áreas costeiras do Instituto Federal do Rio de Janeiro) IFRJ, 2017. Mimeo.

Ballestrin, L. América Latina e o giro decolonial. Revista Brasileira de Ciência Política, 11, 89-117, 2013.

Ballestrin, L. Colonialidade e Democracia. Revista Estudos Políticos, 5(1), 191-209, 2014. Disponível em: http:// 
revistaestudospoliticos.com/wp-content/uploads/2015/02/ Vol.5-N.1-p.191-209.pdf

Brasil. Decreto Lei 271 de 28 de fevereiro de 1967.

Brasil. Decreto $n^{\circ}$ 98.897, de 30 de janeiro de 1990.

Brasil. Lei ${ }^{\circ}$ 9.985, de 18 de julho de 2000. Regulamenta o art. 225, § $1^{\circ}$, incisos I, II, III e VII da Constituição Federal, institui o Sistema Nacional de Unidades de Conservação da Natureza e dá outras providências.

Brasil. Portaria Interministerial $n^{\circ} 436$ de 2 de dezembro de 2009.

Brasil /MMA. Parecer 016/95 do Centro Nacional de Populações Tradicionais - CNPT, 1995.

Brasil/MMA. Portaria ${ }^{\circ} 17-N$, de 18 de fevereiro de 1999. Plano de Utilização da Reserva Extrativista Marinha do Arraial do Cabo.

Brasil /MMA. Estudo de capacidade de carga náutica para as áreas de serviços com potencial de concessão na Reserva Extrativista Marinha do Arraial do Cabo, 2011.

Castro-Gómez, S. Ciências sociais, violência epistêmica e o problema da 'invenção do outro'. In: Lander, E. (Org.). A colonialidade do saber: eurocentrismo e ciências sociais, perspectivas latino-americanas. Buenos Aires: Clacso, 2005.

CDREMAC - Conselho Deliberativo da Reserva Extrativista Arraial do Cabo. Regimento Interno. 17/04/2013.

Cruz, V. do C. Geografia e pensamento decolonial: notas sobre um diálogo necessário para a renovação do pensamento crítico. In: Cruz, V. do C.; Oliveira, D. A. (Orgs.). Giro descolonial: experiências, ideias e horizontes de renovação do pensamento crítico. Rio de Janeiro: Letra Capital, 2017.

Cunha, C. C. Reservas extrativistas: institucionalização e implementação no estado brasileiro dos anos 1990.Tese (Programa de Pós-Graduação em Psicossociologia de Comunidades e Ecologia Social - EICOS) - UFRJ, 2010.

Dagnino, E. Políticas de ciudadanía y sociedad civil en tiempos de globalización. In: Mato, D. (Coord.). Sociedade civil, participação e cidadania: de que estamos falando? Caracas: FACES, Universidad Central de Venezuela, 95110, 2004. Disponível em: http://bibliotecavirtual.clacso. org.ar/Venezuela/faces-ucv/20120723055520/Dagnino.pdf
ICMBio. Instrução Normativa $n^{\circ} 02,18$ de setembro de 2007.

ICMBio. Instrução Normativa $n^{\circ}$ 29, 5 de setembro de 2012.

ICMBio. Instrução Normativa $n^{\circ} 35,27$ de dezembro de 2013.

ICMBio. Conselhos Gestores de Unidades de Conservação Federais: um guia para gestores e conselheiros. Coordenação de Gestão Participativa. Brasília: Instituto Chico Mendes de Conservação da Biodiversidade, 2015.

Lobão, R. J. da S. Cosmologias Políticas do Neocolonialismo: como uma política pública pode se transformar em uma política do ressentimento. Niterói: Editora da UFF, 2010.

Lobão, R. J. da S. Quando as associações são voluntárias no Brasil? Uma discussão sobre novas formas de colonialização em Reservas Extrativistas. In: Cefaï, D,; Mello, M.; Mota, A. da S.; Fabio, R. (Orgs.). Arenas Públicas: por uma vida associativa. Niterói, Editora da UFF, 2011.

Maldonado-Torres, N. Sobre la colonialidad del ser: contribuciones al desarrollo de un concepto. In: Castro-Gómez, S.; Grosfoguel, R. (Coords.). El giro decolonial. Reflexiones para una diversidad epistémica más allá del capitalismo global, 2007. p.127-167.

Maranhão, T. C. Significados da Pactuação entre Órgãos Públicos Ambientais e Populações Tradicionais. Dissertação (Mestrado em Sociologia e Direito) - UFF, 2012

Milani, C. R. S. O princípio da participação social na gestão de políticas públicas locais: uma análise de experiências latino-americanas e europeias. 2008. Revista de Administração Pública, 42(3), 551-79, 2008. Disponível em : http://www. scielo.br/pdf/rap/v42n3/a06v42n3.pdf/

Porto-Gonçalves, C. W. Geografando: nos varadouros do mundo: da territorialidade seringalista (o seringal) à territorialidade seringueira (a reserva extrativista). Brasília, Ibama, 2003.

Quijano, A. Colonialidade do poder. A colonialidade do saber: eurocentrismo e ciências sociais. Perspectivas latino-americanas. Buenos Aires: CLACSO, 2005.

Santos, B. de S.; Avritzer, L. Introdução:para ampliar o cânone democrático. In: Santos, B. de S. (Org.). Democratizar 
a Democracia: os caminhos da Democracia Participativa. Civilização Brasileira, Rio de Janeiro, 2002.

Santos, B. de S.; Meneses, M. P. G. de; Nunes, J. A. Introdução: para ampliar o cânone da ciência: a diversidade epistemológica do mundo. In: Santos, B. de S. (Org.). Semear outras soluções: os caminhos da biodiversidade e dos conhecimentos rivais. Civilização Brasiliera, Rio de Janeiro, 2005.

Sayago, D. Participação: olhar para fora ou olhar para dentro. Ra Ximhai, 4(3), 543-558, 2008.

Souza, J. M. Os limites da democracia participativa a partir da perspectiva das teorias decoloniais. In: Anais da Semana de Ciências Sociais da Universidade Federal doEspiritoSanto,2014. Disponível emhttp://www.publicacoes.ufes.br/ SCSUFES/article/view/8568

Souza Lima, A. C. Sobre gestar e gerir a desigualdade: pontos de investigação e diálogo. In: Souza Lima, A. C. (Org.). Gestar e Gerir: estudos para uma Antropologia da Administração Pública no Brasil. Rio de Janeiro, Relume-Dumará, 2002, p. 11-21.

Spínola, J. L. Participação e Deliberação na Resex Marinha do Pirajubaé (SC). Curitiba, Tese (Programa de Pós-graduação Interdisciplinar em Meio Ambiente e Desenvolvimento) - UFPR, 2012. 